Programa de Residência Pedagógica na Licenciatura em Informática: partilhando possibilidades

\title{
FORMAÇÃO DE PROFESSORES, PRÁTICA DE ENSINO E O PROGRAMA DE RESIDÊNCIA PEDAGÓGICA
}

Breno Trajano de Almeida ${ }^{1}$, Karina de Oliveira Lima ${ }^{2}$

PALAVRAS-CHAVE

Formação de Professores;

Teoria e Prática;

Residência Pedagógica.

\section{RESUMO}

Uma das questões mais complexas para o campo da formação de professores diz respeito às experiências em que se possam articular conhecimentos com a prática docente. Desde os mais remotos registros de organização humana, a presença de quem ensina/educa/transmite é constante, embora as discussões sobre a necessidade de formação específica não ultrapassem dois ou três séculos. Neste capítulo, ao lado de breves relatos sobre a formação de professores e antecedentes da Residência Docente no Brasil, buscamos referenciais que apontam para a necessidade de uma formação que inclua a prática docente na perspectiva de superar a mera instrumentalização dos futuros professores.

\section{INTRODUÇÃO}

A problemática da formação docente não se restringe à busca pela garantia da formação inicial, mas envolve também a qualidade dela. É no contexto de ressignificar a formação docente, numa perspectiva qualitativa, que o Programa de Residência Pedagógica (PRP) se configura como uma política que visa garantir uma efetiva articulação da teoria com a prática, premissa amplamente preconizada pelas pesquisas nacionais e internacionais. (PIMENTA; LIMA, 2012).

Segundo Pimenta (1999), antes do PRP, o estágio docente supervisionado já vinha incorporando mudanças na direção de superar a dicotomia teoria e prática, bem como, o combate à concepção de que na prática a teoria é outra. Quem passa por cursos de licenciatura sente-se desafiado quando assume pela primeira vez uma sala de aula, embora na graduação tenha cumprido toda a jornada de estágio.

De acordo com Nóvoa (1995), esta nova abordagem se contrapôs aos estudos anteriores que limitavam o exercício docente a um conjunto de competências e técnicas criando uma angústia dicotômica entre o eu profissional e o eu pessoal.

Dentre as demandas educacionais contemporâneas, o professor é um profissional "do qual é exigido uma dupla formação: nos saberes de sua área disciplinar e curricular (linguagens, matemática, ciências da natureza ou ciências humanas) e do saber ensinar (da pedagogia e da experiência docente e cultural)" diz

1 Professor Efetivo do Instituto Federal de Educação, Ciência e Tecnologia do Rio Grande do Norte (IFRN) - Campus Ipanguaçu; Orientador do Programa de Residência Pedagógica. E-mail: breno.almeida@ifrn.edu.br

2 Professora Efetiva do Instituto Federal de Educação, Ciência e Tecnologia do Rio Grande do Norte (IFRN) - campus São Paulo do Potengi; Preceptora do Programa de Residência Pedagógica. E-mail: Karina.lima@ifrn.edu.br 
Therrien (2015, p. 1), superando a visão funcionalista da educação, apontada por Feldens (1984), em que predominava a preocupação em relação ao treinamento de professores. É nesse contexto, de estágio enquanto campo de conhecimento, que se insere o Programa de Residência Pedagógica.

\section{FORMAÇÃO DE PROFESSORES: UM BREVE HISTÓRICO}

$\mathrm{O}$ ato de ensinar é uma ação eminentemente humana que existe como forma de transmissão e acumulação de conhecimentos historicamente produzidos pelo homem, mas é somente a partir do século XVII que são encontrados os primeiros registros evocando a necessidade de formação docente. Segundo Aranha (2006), com base nos estudos da história da educação, nem sempre a problemática da formação docente esteve em destaque e recebeu a importância necessária.

Atrelado a esse fato, encontram-se a propagação de ideias errôneas que associam o ser professor à imagem do missionário, um ser dotado de uma vocação para ensinar e de generosidade, constituindo requisitos necessários para o exercício da docência. Isto é, deflagrando que para ser professor não era preciso uma formação especializada.

De acordo com Duarte (1986), o primeiro estabelecimento de ensino voltado à instrução de professores foi o Seminário dos Mestres idealizado por São Batista de La Salle, datado de 1684, em Reims, França.

Ainda no século XVII, a obra Didática Magna, de Comenius, legitimou o "surgimento da didática enquanto teoria de ensino, proveniente da necessidade de planejamento, estruturação e organização dessa atividade” (LIBÂNEO, 1994, p. 8). Demonstrando, assim, o entrecruzamento entre formação de professores e a didática.

Ao longo dos séculos, as demandas formativas advindas a partir dos processos de reestruturação dos modos de produção e organização social intensificaram as exigências do homem a ser formado e, consequentemente, a escola é convocada a se adequar a essas exigências e as agências formativas não ficam ilesas: são igualmente provocadas a se alinharem aos preceitos de cada época.

No entanto, a formação de professores, enquanto demanda de ação governamental, só aparece no final do século XIX, como consequência da necessidade de instrução popular, após a Revolução Francesa, derivando a criação de Escolas Normais como instituições encarregadas de preparar professores. (SAVIANI, 2009).

No Brasil, a expulsão dos jesuítas, certamente os primeiros profissionais da educação a atuarem aqui, criou um vácuo de descontinuidade e carência para o exercício docente, tanto que, a primeira Lei de Ensino brasileira é o Decreto Imperial de 15 de outubro de 1827 (data posteriormente transformada em Dia do Professor), e respondia ao disposto no Art. 179, da Constituição Federal brasileira de 1824, a instrução primária é gratuita para todos os cidadãos.

Contemplando elementos que seriam o foco da valorização docente, como a fixação de ordenados dos Professores, e determinando que o ensino deveria ser 
desenvolvido pelo método mútuo $^{3}$, essa Lei estipulou que os professores seriam treinados nesse método, às próprias custas, nas capitais das respectivas províncias. (BRASIL, 1827).

Para Saviani, "está colocada à exigência de preparo didático, embora não se faça referência propriamente à questão pedagógica" (2009, p. 144). Em 1835, seguindo a tendência europeia de formação de professores via Escolas Normais, a primeira dessas instituições, no Brasil, foi criada em Niterói/RJ.

Como se percebe, a formação tem sido apontada como fundamental para o exercício profissional e melhoria da educação. Em 1996, a Lei de Diretrizes e Bases da Educação Nacional - Lei no 9.394/1996 - propôs elevar a escolarização para ingresso na carreira docente estabelecendo Licenciatura ou Normal Superior, porém admitindo como formação provisória o curso normal ou magistério para a Educação Infantil e séries iniciais do Ensino Fundamental.

Naquele ano, o Censo Escolar da Educação Básica, divulgado pelo Instituto Nacional de Estudos e Pesquisas Educacionais Anísio Teixeira (INEP), registrava que $8,1 \%$ das funções docentes nas séries iniciais eram ocupadas por professores somente com formação de ensino fundamental. Atualmente, dados ${ }^{4}$ apontam que esse percentual caiu para $0,3 \%$ dentre os $22,5 \%$ de docentes sem nível superior atuando em escolas no Brasil. No Nordeste, esses percentuais chegam a 0,4\% e 35,3\%, respectivamente.

\section{A PRÁTICA DOCENTE E O PROGRAMA DE RESIDÊNCIA PEDAGÓGICA}

A questão da "prática" na formação de professores não é nova. Therrien (1997, p. 7) afirma que os estudos sobre a formação do professor persistiam "numa dissociação entre a formação e a prática cotidiana, não enfatizando a questão dos saberes da experiência, da prática social e da cultura."

Nóvoa (1995, p. 19) enfatiza que a identidade docente tem relação com sua própria história de vida, "em outros modos de apreensão da realidade que não sejam apenas aqueles privilegiados pela razão instrumental e a racionalidade técnica e científica". Para este autor, a bagagem teórica terá pouca utilidade, se você não fizer uma reflexão global sobre sua vida, como aluno e como profissional.

Em 2007, o Projeto de Lei do Senado no 227/2007 propunha um programa denominado residência educacional, obrigatório e posterior à habilitação dos professores para a docência na educação infantil e nos anos iniciais do ensino fundamental (BRASIL, 2007). O referido Projeto foi arquivado em 2011. Em 2012, houve proposta para reapresentá-lo, mas alterando o nome para residência pedagógica e, sem obrigatoriedade para o exercício profissional.

3 O método Lancaster, também conhecido como Ensino Mútuo ou Monitorial, teve como objetivo ensinar um maior número de alunos, usando pouco recurso, em pouco tempo e com qualidade. Foi criado por Joseph Lancaster, influenciado pelo trabalho do pastor anglicano Andrew Bell.

${ }^{4}$ Anuário Brasileiro da Educação/2019. 


\section{Breno Trajano E Karina Lima}

Essas duas propostas, bem como a do Programa Residência Docente, iniciado, em caráter experimental, no Colégio Pedro $\mathrm{II}^{5}$, consideram essa atividade como formação complementar, posterior à conclusão da habilitação. Com esse mesmo princípio, em 2013, a Coordenação de Aperfeiçoamento de Pessoal de Nível Superior (CAPES) aprovou o Projeto Residência Docente, do Centro Pedagógico da Universidade Federal de Minas Gerais (CP/UFMG), atendendo, de início, professores da rede municipal de ensino de Contagem/MG. Com a suspensão das bolsas pela CAPES, em 2016, os professores do CP/UFMG se organizaram e propuseram a instituição de um curso de especialização (latu sensu) intitulado Residência Docente para Formação de Educadores da Educação Básica, que teve início em agosto de 2018.

Enquanto atividade que ocorre durante o curso de habilitação docente, o primeiro Programa de Residência Pedagógica foi implementado em 2009, no curso de Pedagogia da Universidade Federal de São Paulo (UNIFESP), onde os cursistas vivenciam, a partir da segunda metade do curso, quatro modalidades: “docência em Educação Infantil, docência nos anos iniciais do Ensino Fundamental, docência em Educação de Jovens e Adultos e Gestão Educacional" (FARIA; PEREIRA, 2019, p. 340).

Cada modalidade tem a carga horária dividida entre os encontros com o professor preceptor e as atividades do período de imersão. Segundo Giglio e Lugli (2013, p. 65) o "princípio da imersão" tem relação com a "experiência da tradição de formação médica" pelo "vínculo do residente com as escolas-campo de forma intensa, sistemática e por um período limitado". Na mesma linha do princípio de imersão, outras experiências de residência são desenvolvidas: 1) o Projeto Imersão Docente (PID) realizado pelo Centro Pedagógico (CP) da Escola de Educação Básica e Profissional da UFMG, para formar professores para o exercício docente na educação integral (CENTRO PEDAGÓGICO, 2013) e, 2) o Programa Residência Educacional da Secretaria de Estado da Educação de São Paulo (SÃO PAULO, 2012), onde estudantes de cursos de licenciatura realizavam o estágio curricular obrigatório nos anos finais do Ensino Fundamental e do Ensino Médio nas escolas com baixos índices de desempenho escolar, atestados no Sistema de Avaliação do Rendimento Escolar do Estado de São Paulo (SARESP).

Segundo Carvalho et al. (2015, p. 15), a Política Nacional de Formação de Profissionais do Magistério da Educação Básica, instituída pelo Decreto $\mathrm{n}^{\circ}$ 6.755/2009, inaugurou na história brasileira "a possibilidade de se organizar, sob regime de colaboração entre os entes federados, a formação inicial e continuada do magistério da Educação Básica para as redes públicas de ensino".

O atual Programa de Residência Pedagógica (PRP), instituído pela Portaria $\mathrm{n}^{\mathrm{o}}$ 38, de 28 de fevereiro de 2018, da CAPES/Ministério da Educação, tem por finalidade apoiar Instituições de Ensino Superior (IES) na implementação de projetos inovadores que estimulem a articulação entre teoria e prática nos cursos de

${ }^{5}$ Oficialmente instituído pela CAPES por meio da Portaria ${ }^{\circ}$ 206, de 21 de outubro de 2011. 
licenciatura, conduzidos em parceria com as redes públicas de educação básica, e por objetivos: (BRASIL, 2018a).

I. Aperfeiçoar a formação dos discentes dos cursos de licenciatura, por meio do desenvolvimento de projetos que fortaleçam o campo da prática e que conduzam o licenciando a exercitar de forma ativa a relação entre teoria e prática profissional docente, utilizando coleta de dados e diagnóstico sobre o ensino e a aprendizagem escolar, entre outras didáticas e metodologias;

II. Induzir a reformulação do estágio supervisionado nos cursos de licenciatura, tendo por base a experiência da residência pedagógica;

III. Fortalecer, ampliar e consolidar a relação entre a IES e a escola, promovendo sinergia entre a entidade que forma e aquelas que receberão os egressos das licenciaturas, além de estimular o protagonismo das redes de ensino na formação de professores; e

IV. Promover a adequação dos currículos e das propostas pedagógicas dos cursos de formação inicial de professores da educação básica às orientações da Base Nacional Comum Curricular (BNCC).

O Edital CAPES no 06/2018, que é a chamada pública para apresentação de propostas no âmbito do PRP, estabelece que o Programa será realizado em regime de colaboração, por formalização de Acordo de Cooperação Técnica (ACT), firmado entre o Governo Federal, por meio da CAPES, e o Conselho Nacional de Secretários de Educação (CONSED), a União Nacional dos Dirigentes Municipais de Educação (UNDIME), as Secretarias de Educação dos Estados, do Distrito Federal e dos Municípios e os dirigentes máximos das escolas e instituições da rede federal de ensino que ofertam educação básica. (BRASIL, 2018b).

Ademais, estabelece que para efetivar a colaboração, as Secretarias de Educação organizarão o Comitê de Articulação da Formação Docente da Unidade Federativa, composto por representantes da rede estadual e municipal que aderirem ao Programa, que também será responsável pela articulação, acompanhamento e avaliação dos projetos de residência pedagógica desenvolvidos no âmbito de suas redes.

O Projeto Institucional do IFRN, registrado na Plataforma CAPES, também conhecida como Plataforma Freire, destaca que o estágio das licenciaturas, integrado com o PRP, deve se constituir em uma oportunidade de ensino com pesquisa e extensão, principalmente por meio das oportunidades de estudo de caso em escolas, proporcionando a produção de conhecimento de autoria de residentes e de preceptores na medida em que ressignificam o seu fazer pedagógico. (IFRN, 2018).

$\mathrm{O}$ avanço tecnológico na informação e comunicação cria uma emergência formativa em todos os setores da sociedade, mas muito mais para os que se dedicam à educação de crianças e jovens, cada vez mais próximas das facilidades tecnológicas. As exigências formativas para o exercício docente emergem, dessa forma, num contexto de informações e de transformações extremamente rápidas, o que nos leva a compreender que a especificidade da 'profissão-professor' transcende o 


\title{
Breno Trajano \& Karina Lima
}

conhecimento curricular e demanda um ofício que envolva saberes próprios e específicos da docência (GAUTHIER et al., 2013).

Dessa forma, o PRP, ao induzir o aperfeiçoamento do estágio curricular supervisionado, por meio da imersão do licenciando, que esteja na segunda metade do curso, numa escola de educação básica, ${ }^{6}$ corrobora a necessidade de "produzir um outro tipo de conhecimento, mais próximo das realidades educativas e do cotidiano dos professores" (NÓVOA, 1995, p.19).

No IFRN, no Campus Ipanguaçu, o PRP tem propiciado aos residentes do curso de Licenciatura em Informática, perceber que existem atividades 'antes, durante e depois' da ação docente propriamente dita e, essa percepção, combinada com a vivência da sala de aula, tem demonstrado que é indispensável transformar experiências, tanto individuais, quanto coletivas, em conhecimento profissional, e que esse se constitua, conforme nos lembra Freire (2005), em base para reflexão e debate sobre novas possibilidades educativas, engendrando um movimento cíclico de ação-reflexão-ação.

Nesse sentido, a implementação do PRP por meio da Licenciatura em Informática, vai além dos objetivos propostos, visando também, nesse espaço em que as realidades se encontram, evidenciar a importância da informática e a sua relevância no cotidiano da aprendizagem, tanto para os professores, quanto para os estudantes da educação básica. É, dessa forma, uma oportunidade de ampliar espaços de atuação, de integrar conhecimentos e de se identificar como docente, uma vez que essa identidade "não é um dado adquirido, não é uma propriedade, não é um produto" (NÓVOA, 1995, p. 34). A identidade é um lugar de lutas e conflitos, é um espaço de construção de maneiras de ser e estar na profissão.

De acordo com Pimenta e Gonçalves (1990), a finalidade do estágio é propiciar ao aluno uma aproximação à realidade na qual atuam e não apenas a parte prática do curso. Essa postura, presente no Programa de Residência Pedagógica, redefine o estágio que deve caminhar para a reflexão, a partir da realidade. Realidade essa que pode, inclusive, desafiar um licenciando em Informática a superar a falta de um laboratório de informática em suas atividades.

Desse modo, concordamos com Pimenta e Lima (2012, p. 14) quando afirmam:

\begin{abstract}
Ao confrontar suas ações cotidianas com produções teóricas, impõe-se rever suas práticas e as teorias que as informam, pesquisando a prática e produzindo novos conhecimentos para a teoria e a prática de ensinar. Assim, as transformações das práticas docentes só se efetivam a medida que o professor amplia sua consciência sobre a própria prática, a de sala de aula e a da escola como um todo, o que pressupõe os conhecimentos teóricos e críticos sobre a realidade (grifos do autor).
\end{abstract}

Em outras palavras, um contexto capaz de propiciar ao futuro professor uma visão mais abrangente do caráter coletivo e social de sua profissão, visto que ser

\footnotetext{
${ }^{6}$ https://www.capes.gov.br/36-noticias/8778-capes-publica-editais-do-pibid-e-do-novo-programa-de-residenciapedagogica
} 


\section{Breno Trajano E Karina Lima}

professor é uma profissão e, como tal, requer formação qualificada, saberes, habilidades e competências que dialoguem com o tempo hodierno, marcado pelas múltiplas relações dos contextos econômicos, sociais, culturais e científicos que forjam os históricos e as realidades e, consequentemente, impõem exigências formativas.

Assim, ser professor, cada vez mais, requer uma formação plural, constituindo-se como fator primordial para o sucesso de reformas educativas. Um bom exemplo do importante papel desse profissional no arranjo das mudanças educacionais é o significado do "fator professor", expressão cunhada por Gauthier (2006, p.33).

A importância deste fator é tal que, nos últimos anos, muitas das reformas apresentadas em vários países para garantir o sucesso educativo dos alunos colocaram o professor no âmago das mudanças almejadas.

Assim, em um tempo marcado pela velocidade da informação, é necessário romper com as amarras da alienação massificada e massificante e desenvolver a criticidade pautada em conhecimentos científicos e aprender a questionar, duvidar e, mesmo sem ter todas as respostas, desenvolver a capacidade de ir buscá-las, lançarse às indagações, reflexões (ARANHA, 2006).

Isto requer a formação de um professor pesquisador do seu próprio fazer. Aquele que assume a sua prática como o próprio objeto de conhecimento, sendo um professor reflexivo a partir de questões reais, vivenciadas na e pela escola e ressignificada num contexto contínuo de análise crítica-reflexiva das práxis educativas.

\section{CONSIDERAÇÕES FINAIS}

Em meio às realidades desiguais e dificuldades diversas, professores e professoras se consolidam como aprendizes diários, numa prática constante que fortalece sua identidade profissional. Ter a oportunidade de iniciar essa constante reconstrução enquanto ainda cursista, certamente dará aos futuros docentes uma base mais sólida para enfrentar os desafios de ser professor.

Assim, ainda que pesem contradições ao atual PRP, especialmente pela vinculação com a BNCC e pela aparente oposição deflagrada ao importante Programa PIBID, é possível afirmar a existência de possibilidades criativas e reflexivas em suas práxis.

A exemplo do PRP desenvolvido pelo IFRN, muitos projetos institucionais foram consubstanciados de forma séria a partir de trabalhadores docentes que acreditam na educação como um caminho coletivo a ser percorrido entre estradas íngremes, mas com oásis que permitem a ressignificação do processo.

Não obstante, importa lembrar que paralelamente às oportunidades criadas pelos programas PRP e PIBID, destacadamente no contexto do encerramento dos 


\section{Breno Trajano E Karina Lima}

seus primeiros editais em 2020, o contexto da política educacional se apresenta de forma conturbada, com perseguição às instituições públicas de ensino superior, corte de recursos, descaso com as condições de trabalho, carreira e remuneração para profissionais que já estão em exercício nas escolas.

\section{REFERÊNCIAS}

ARANHA, M. L. de A. Filosofia da Educação. $3^{\text {a }}$ Ed. São Paulo: Moderna, 2006.

BRASIL. Decreto-Lei Imperial, de 15 de outubro de 1827. Disponível em:

<http://www.adur-rj.org.br/5com/pop-up/ decreto-lei_imperial.htm>. Acesso em: 03. nov. 2019.

BRASIL. Senado Federal. Projeto de Lei do Senado n²27. Brasília: Senado Federal, 2007.

BRASIL. Ministério da Educação. Coordenação de Aperfeiçoamento Pessoal de Nível Superior - CAPES. Portaria $\mathbf{n}^{\mathbf{0}}$ 38, de 28 de fevereiro de 2018. Institui o programa de Residência Pedagógica. Brasília, DF: 2018a. Disponível em: http://www.in.gov.br/materia/-

/ asset_publisher/Kujrw0TZC2Mb/content/id/5230849/do2-2018-03-05-portaria-n38-de-28-de-fevereiro-de-2018-5230845. Acesso em: 2 jan. 2019.

BRASIL. Ministério da Educação. Coordenação de Aperfeiçoamento Pessoal de Nível Superior - CAPES. Edital CAPES $\mathbf{n}^{0}$ 6, de $1^{\circ}$ de março de 2018. Chamada Pública para apresentação de propostas no âmbito do Programa de Residência Pedagógica. Brasília, DF: 2018b. Disponível em: https:/ / www.capes.gov.br/images/stories/download/editais/01032018-Edital-62018-Residencia-pedagogica.pdf. Acesso em: 2 jan. 2019.

CARVALHO, J. do P. F. de et al. Programa Institucional de Bolsa de Iniciação à Docência: apontamentos sobre editais e formação de professores da Educação Básica. In: FARIAS, I. M. S. de; JARDILINO, J. R. L.; SILVESTRE, M. A. (Org.). Aprender a ser professor: aportes de pesquisa sobre o PIBID. Jundiaí: Paco Editorial, 2015, p. 1529.

CENTRO PEDAGÓGICO (UFMG). Projeto de Ensino: Imersão Docente. Belo Horizonte: Universidade Federal de Minas Gerais, 2013, 12p.

DUARTE, S. G. Dicionário brasileiro de educação. Rio de Janeiro: Antares/Nobel. 1986.

FARIA, J. B.; PEREIRA, J. E. D. Residência pedagógica: afinal, o que é isso? R. Educ. Públ. Cuiabá. v. 28, n. 68, p. 333-356, mai./ago. 2019. 
FELDENS, M. G. F. Educação de professores: tendências, questões e prioridades. Tecnologia Educacional. Rio de Janeiro, v. 13, n. 61, p. 16-26, nov./dez. 1984.

FREIRE, Paulo. Pedagogia da Autonomia: saberes necessários à prática educativa. $31^{\mathrm{a}}$ ed. Rio de Janeiro: Paz e Terra, 2005.

GAUTHIER, C. et al. Por uma teoria da Pedagogia. Pesquisas contemporâneas sobre o saber docente. Ijuí-RS: Editora INIJUI, 2013.

GIGLIO, C. M. B; LUGLI, R. S. G. Diálogos pertinentes na formação inicial e continuada de professores e gestores escolares. A concepção do programa de residência pedagógica na UNIFESP. Cadernos de Educação, Pelotas, 46, p. 62-82, 2013.

IFRN. Projeto Pedagógico do Curso Superior de Licenciatura em Informática. Natal/RN: Pró-Reitoria de Ensino, 2018.

LIBÂNEO, J. C. Didática. São Paulo, Cortez, 1994.

NÓVOA, A. Diz-me como ensinas, dir-te-ei quem és e vice-versa. In: FAZENDA, I.(org.). A pesquisa em educação e as transformações do conhecimento. Campinas: Papirus. 1995.

NÓVOA, A. Os professores e as histórias da sua vida. In: (Org.). Vidas de professores. Porto: Porto Editora. 1995.

NÓVOA, A. Entrevista concedida por e-mail, da capital portuguesa, para a Revista Nova Escola/Paola Gentile. Disponível em:

https:/ / novaescola.org.br/conteudo/179/entrevista-formacao-antonio-novoa

Acesso em: out. 2019.

PIMENTA, S. G. Formação de professores: identidade e saberes da docência. In: PIMENTA, Selma Garrido. (Org). Saberes pedagógicos e atividade docente. São Paulo: Cortez Editora, 1999. (p. 15 a 34).

PIMENTA, S. G; GONÇALVES, C. L. Revendo o ensino de $\mathbf{2}^{\mathbf{0}}$ grau, propondo a formação do professor. São Paulo: Cortez, 1990.

PIMENTA, S. G.; LIMA, M. S. L. Estágio e docência. São Paulo: Cortez, 2012.

SÃO PAULO, Decreto $\mathrm{n}^{\mathrm{o}}$ 57.978, DE 18 de abril de 2012. Disponível em: https://www.al.sp.gov.br/norma/166818 Acesso em out. 2019

SAVIANI, D. Prefácio. In: ARAÚJO, José Carlos S.; FREITAS, Anamaria Gonçalves B.; LOPES, Antônio de Pádua C. (org.). As Escolas Normais no Brasil: do império à república. $2^{a}$ ed. Campinas. SP: Editora Alínea, 2017.

SAVIANI, D. Formação de professores: aspectos históricos e teóricos do problema no contexto brasileiro. Rev. Bras. Educ. vol.14, no ${ }^{\circ}$ 40, Rio de Janeiro Jan./ Abr. 2009. 
TARDIF, Maurice. Saberes docentes e formação profissional. $4^{\mathrm{a}}$ Ed. Rio de Janeiro: Vozes, 2002.

THERRIEN, J. Saber da experiência, identidade e competência profissional: como os docentes produzem sua profissão. Revista Contexto e Educação. Ed. UNIJUI, vol.12, $n^{\circ} 48$, p.7-36, 1997.

Formação Continuada de Professores. 2015. Disponível em:

http://jacquestherrien.com.br/wpcontent/uploads/2015/10/Forma \%C3\%A7\%C3\%A3o-continuada-de-professoresreflex\%C3\%B5es-te\%C3\%B3rico-pr\%C3\%A1ticas.pdf Acesso: out. 2019 